\title{
Mine closure plans: assumptions and optimism
}

\author{
G Byrne Niboi Consulting, Australia
}

\begin{abstract}
Because planned closure is often many years into the future many closure plans have a set of underlying assumptions. Sometimes these are well documented, but more often they are inferred within the framework of the closure concept and do not always receive appropriate focus. Even when closure plans document assumptions the list is often incomplete.

It is entirely appropriate for closure plans to be based on assumptions. Indeed, assumptions will need to be made regarding the feasibility of the closure concept, regulatory regime, schedules, criteria achievement, mine life etc. Sometimes assumptions are conservative although often, however, assumptions are based on an optimism bias, in which case these assumptions really equate to risks if the assumptions do not come to fruition.

It is therefore imperative that all underlying assumptions in a closure plan that can potentially have a material impact on outcomes and cost are identified and documented. However, the closure plan cannot simply just list and thereafter ignore them. The risks of the assumption not eventuating need to be assessed and incorporated into the closure risk register and possibly into a revision of the closure plan itself. Those risks will also need to be analysed and quantified in terms of the potential impact to closure costs.
\end{abstract}

This paper discusses a framework for capturing the assumptions that underlie many closure plans, their transition into closure risks and how they should be addressed by the closure plan and associated closure cost estimates. The paper also discusses examples of typical closure plan assumptions and cases where optimism has not been realised.

Keywords: closure assumption, closure risks, optimism

\section{Introduction}

Because closure is often many years into the future many closure plans are necessarily based on multiple assumptions. Sometimes these are well documented, but more often they are inferred within the framework of the closure concept and do not receive appropriate focus. Even when closure plans document assumptions the list is often incomplete. Sometimes underlying assumptions forming the basis of the closure concept are just lost or forgotten over the years, or carried over from year to year with each iteration.

Many closure plans that list assumptions really just describe adopted closure design parameters, such as '...a final tailings dam cap of $0.5 \mathrm{~m}$ of inert material has been assumed...'. This does not describe the assumptions underlying that design, for example that the proposed cap will be sufficient to maintain a long-term stable landform consistent the agreed post mining land uses or that such a cap will satisfy regulator requirements.

It is entirely appropriate for closure plans to be based on assumptions. Indeed, because closure is often many years into the future and basic data is often not available, assumptions will need to be made regarding the feasibility of the closure concept, regulatory regime, schedules, criteria achievement, mine life, etc.. Sometimes assumptions are conservative although typically they have an optimism bias. In such cases these assumptions represent associated risks if they do not come to fruition. Often the risk assessment process ignores the underlying assumptions in a closure plan. It is therefore imperative that all assumptions in a closure plan that can have a material impact on outcomes and cost are identified and documented. 


\section{Assumption examples}

Assumptions in closure plans are many and varied. A simple evaluation of closure plan practices was undertaken for this paper by reviewing 68 closure plans for a range of sites and global localities. Of these, 41 listed assumptions, but in 20 of these closure plans, the assumptions were predominantly describing the adopted bases of closure design - that is, they did not document the underlying assumptions behind the closure design. Surprisingly, 12 of the 68 closure plans did not even contain the word 'assumption'.

Some common issues about which underlying assumptions are made include:

- Landform design.

- Water treatment and management.

- Post execution phase management.

- Stakeholder requirements and expectations.

- Waste management.

- Soil and groundwater contamination.

\subsection{Landform design}

Common assumptions underlying closure landform design relate to the nature and types of caps for tailings storage facilities (TSFs) and waste rock dumps (WRDs). Because final closure design has not been implemented for most closure plans (or in many cases even tested or trialled), assumptions have to be made about many design features such as the final capping. Such assumptions need to be made because there is little data available on such factors as the nature of the final waste materials; their potential for acid and metalliferous drainage generation; how a vegetative cap will perform; post mining land use and landform; the need for capillary breaks; and many other factors.

Often, the assumptions that are made in the early days of closure planning are optimistic, especially around the thickness of the cap, need for surface reshaping for watershed management and such other requirements as capillary breaks. Other common assumptions underlying landform design for closure relate to final slope angles for WRD slopes and TSF embankments. Particularly in the early stages of mine planning, assumptions are made that operational slope angles will be equally applicable for long-term post mining slopes. Such assumptions are frequently driven by a failure to recognise the ready access to slope maintenance personnel and equipment during operations, compared to a post mining situation where such capabilities may not be available. There is also a failure to recognise that standards for landform stability differ in an operational scenario to the long-term post mining situation. Examples of common assumptions are presented in Table 1.

Table 1 Examples of underlying assumptions to landform closure design (continued next page)

\begin{tabular}{ll}
\hline Underlying Assumption & Underlying Assumption \\
\hline There is enough topsoil, capping material & $\begin{array}{l}\text { A flat upper land surface for the TSF and WRD will } \\
\text { be non-eroding and have long-term stability }\end{array}$ \\
$\begin{array}{l}\text { Non-acid forming rock will be available within the } \\
\text { project area }\end{array}$ & $\begin{array}{l}\text { A stable vegetated surface will be able to be } \\
\text { established with no ongoing maintenance being } \\
\text { required }\end{array}$ \\
$\begin{array}{ll}\text { Capillary breaks will not be required } \\
\text { TSF/WRD cap thickness will only need to be } 0.3 \mathrm{~m},\end{array}$ & $\begin{array}{l}\text { Successful revegetation will be achieved with the } \\
\text { proposed } 0.2 \mathrm{~m} \text { depth of topsoil }\end{array}$ \\
$\begin{array}{l}\text { A solution will be found to solve the shortfall in } \\
\text { topsoil inventory at no additional cost }\end{array}$ & $\begin{array}{l}\text { Waste rock dumps will be constructed to final } \\
\text { landform design and slopes during operations }\end{array}$
\end{tabular}




\begin{tabular}{|c|c|}
\hline Underlying Assumption & Underlying Assumption \\
\hline $\begin{array}{l}\text { Progressive closure by backfilling of some } \\
\text { completed pits and ramps will be completed over } \\
\text { the life of the mine as part of ongoing operations }\end{array}$ & $\begin{array}{l}\text { Progressive rehabilitation during operations will } \\
\text { reduce the current disturbed footprint at } \\
\text { shutdown }\end{array}$ \\
\hline $\begin{array}{l}\text { All minor site roads to remain for use by future } \\
\text { landowners }\end{array}$ & Current pit slopes will be stable in the long-term \\
\hline $\begin{array}{l}\text { Existing mine equipment will be suitable for the } \\
\text { specific nature of activities required for closure } \\
\text { execution }\end{array}$ & $\begin{array}{l}\text { Locations of potentially acid forming (PAF) } \\
\text { materials are known and well encapsulated }\end{array}$ \\
\hline $\begin{array}{l}\text { Current earthmoving and mining machinery will be } \\
\text { available at the time of decommissioning }\end{array}$ & - \\
\hline
\end{tabular}

\subsection{Water treatment and management}

Water management is often a source of wild assumptions in closure plans. Many closure plans will assume that little or no water treatment will be required post shutdown or at the completion of the closure execution phase. Examples of closure assumptions relating to water treatment and management are presented in Table 2.

Table 2 Examples of water management closure assumptions

\begin{tabular}{ll}
\hline Underlying Assumption & Underlying Assumption \\
\hline $\begin{array}{l}\text { There will be no requirement for water treatment } \\
\text { after production ceases }\end{array}$ & $\begin{array}{l}\text { Long-term or permanent water treatment will } \\
\text { not be required }\end{array}$ \\
$\begin{array}{l}\text { Waste rock dump and tailings storage facility caps will } \\
\text { eliminate poor water quality discharges - even if there } \\
\text { has been little modelling or design for those caps }\end{array}$ & $\begin{array}{l}\text { Water quality issues will [somehow] be resolved } \\
\text { during the closure execution phase }\end{array}$ \\
$\begin{array}{l}\text { Pit lake water quality will be consistent with the } \\
\text { agreed post mining land use }\end{array}$ & $\begin{array}{l}\text { PAF exposed in the base of the pit will be } \\
\text { inundated by water accumulating in the void in } \\
\text { sufficient time to avoid oxidation }\end{array}$ \\
$\begin{array}{l}\text { Capture and treatment of seepage from the final } \\
\text { tailings dam is completed within the five year } \\
\text { monitoring and maintenance period }\end{array}$ & $\begin{array}{l}\text { Closure water treatment costs have been } \\
\text { allowed for the first year of closure }\end{array}$ \\
$\begin{array}{l}\text { Current perimeter toe drains are adequate to control } \\
\text { sediment runoff }\end{array}$ & - \\
\hline
\end{tabular}

\subsection{Post execution phase management}

The period following closure execution works and prior to site relinquishment is also the subject of many inferred assumptions in closure plans. They often relate to the period of monitoring that may be required, which more often than not have an optimism bias. How many closure plans still have allowance that monitoring will only be required for 5 years, 7 years, 10 years? The majority of these closure plans do not detail risks that could occur during this post-closure execution phase. Additionally, the hidden assumption is that monitoring will not identify any problems! Many closure plans also completely ignore the fact that sites will require land management and maintenance in addition to just monitoring. The inherent assumptions common in many closure plans are that:

- There will be no events causing erosion.

- Areas of vegetation will not fail.

- Landholdings will not need to be managed.

- Rates and leases will not need to be paid.

- Communities and other stakeholders will not require engagement.

- Monitoring/maintenance activities will not need oversight and management. 


\section{$2.4 \quad$ Stakeholders}

Many closure plans will be based on assumptions regarding post mining land uses and final landforms that have not yet been finalised or agreed with relevant stakeholders. There are many closure plan examples where there is an inherent assumption that there will be community and regulator acceptance of the proposed final landform, the design of which has been based solely on engineering and cost factors, rather than considering the full range of stakeholder expectations.

There are sometimes assumptions made that government agendas are completely aligned. For example, a closure plan had an inherent assumption that the water allocations for a related and adjacent operation could be utilised to fill the final pit lake. Each operation, however, was regulated by different government departments which did not necessarily have the same accountabilities and objectives for final water uses.

Closure plans often make assumptions (either documented or inherent in the plan) that the proposed water management for the site will meet stakeholder expectations. A common example of this is an assumption that pit lake water quality will be acceptable to all stakeholders - even when the closure plan has a high chance of pit lake water quality deteriorating over time. Other examples of stakeholder assumptions in closure plans are:

- Approval will be gained to simply flush the concentrate slurry pipeline with clean water and then to leave the infrastructure buried.

- There will be no requirements to maintain or monitor heritage structures following completion of mining activities and restoration of the structures.

- All underground services and pipelines, with the exception of fuel lines, will be left in situ.

- Powerline infrastructure to remain post mining.

- Surface infrastructure, such as office and accommodation buildings, will be used by the local community.

- It will be acceptable that foundations will be removed to $0.5 \mathrm{~m}$ depth.

- Closure plan is based on the existing approved life-of-mine plan.

- Marine disposal areas require no closure works.

\subsection{Waste management}

The generation and management of wastes is sometimes an under-estimated issue in closure plans, especially for early stage closure concepts and conceptual closure plans. Hence there are many assumptions that are either inherent or given little regard in the closure plan. Examples of closure plan assumptions relating to waste management are presented in Table 3.

Table 3 Examples of waste management closure assumptions (continued next page)

\begin{tabular}{ll}
\hline Underlying Assumption & Underlying Assumption \\
\hline Demolition costs will be offset by scrap values & $\begin{array}{l}\text { Equipment, steel and related material from the plant } \\
\text { demolition which has salvage value will not be } \\
\text { disposed, but will be salvaged or sold to third parties } \\
\text { Demolition waste will be disposed of in the pit }\end{array}$ \\
$\begin{array}{l}\text { Rehabilitation costs do not include offsite } \\
\text { removal of material }\end{array}$ & $\begin{array}{l}\text { Decommissioning, decontamination and demolition } \\
\text { will have been processed }\end{array}$ \\
$\begin{array}{l}\text { wastes will be disposed of to the existing onsite } \\
\text { landfill - and that the existing landfill has been } \\
\text { designed and constructed for long-term acceptance of } \\
\text { those wastes }\end{array}$
\end{tabular}




\begin{tabular}{ll}
\hline Underlying Assumption & Underlying Assumption \\
\hline $\begin{array}{l}\text { Costs associated with decommissioning of the } \\
\text { plant including flushing of lines, }\end{array}$ & $\begin{array}{l}\text { Inventories of residual raw materials can be sold or at } \\
\text { depressurisation of systems and removal of }\end{array}$ \\
\begin{tabular}{ll} 
hazardous materials will be an operational cost \\
\hline
\end{tabular}
\end{tabular}

\subsection{Soil and groundwater contamination}

A related topic is that of soil and groundwater contamination. Whilst this issue is typically well addressed for those sites with large processing or downstream operations, many mine closure plans do not account for the possible requirement for remediation of such contamination. Of those closure plans that do account for this issue, few incorporate risks that it may be more extensive than estimated. The reasons for this vary, but have underlying assumptions that include:

- The issue will be addressed during operational mine life.

- It will somehow resolve itself by the end of mine life.

- It is not regarded as a 'closure issue'.

- There will be no regulatory requirement to address soil and groundwater contamination.

- The site is too remote or there are no sensitive receptors.

- It is not material in the context of the range of other issues associated with site closure.

\section{Consequences}

The issue is not that assumptions are made in closure plans. Indeed, many of the example assumptions described in the previous section may be entirely reasonable in particular situations and based on an acceptable standard of professional judgement, particularly when at the conceptual closure plan stage. The real issue is that assumptions are not being acknowledged and documented. If assumptions are not properly identified, then risks associated with the closure plan are not properly identified. Importantly, the vulnerabilities of the closure plan are not well understood by key stakeholders, including mine planners and management; closure practitioners; regulators; community groups; corporate executives; and investors. Further, it could mean that the closure plan does not have a sound basis and can threaten stakeholder acceptability and the integrity of closure cost estimates.

The latter has the obvious implications for closure budgets being incorrect and closure provisions reported in company balance sheets potentially being inaccurate. As noted in the previous section, assumptions are often associated with some of the main cost factors of site closure, notably - bulk earthworks and water management.

Section 2 provided many examples of assumptions associated with landform design and associated bulk earthworks. Because most mines have large disturbed footprints then any changes to the design parameters of closure items such as TSF caps and WRD slopes can have multi-million dollar cost implications. Therefore, it is critically important to understand the assumptions upon which these earthworks design parameters have been based. The uncertainties of these assumptions need to be recognised and the risks of them not coming to fruition need to be considered when assessing closure strategy options. Importantly they need to be accounted in closure cost estimates.

Section 2 also provided examples of assumptions associated with water management during closure. As with landform design, it is critical to understand the uncertainties behind these assumptions. How realistic are they? Do they entail unwarranted optimism - or are they overly conservative?

Reviewing closure plan data would suggest that most water management assumptions are optimistic. An evaluation of long-term water management (Byrne \& Hancock 2018) identified a significant gap between what is being predicted in closure plans and the reality of what is required for post mining water management. This paper reviewed 122 closure plans for operational mines and separate data for 73 mines 
in actual closure. It showed that the mines in actual closure had much longer periods to achieve relinquishment than the relinquishment periods assumed in the closure plans. Many of the sites in closure that were reviewed have had to implement water management activities that are much more extensive than initially conceived at shutdown. Clearly, the assumptions that were made about water management requirements did not eventuate in these instances. A common factor for many sites was the time required for water management. Amongst other findings, it noted that:

\section{"...only one site had allowance for long-term (>50 years) water treatment. Of the sites in actual closure, $29 \%$ have reported that they expect such long-term water treatment, with many acknowledging that in perpetuity treatment is probable."}

The review of the closure plans indicated that only a minority acknowledged the risk that post shutdown water treatment might be required, even when water quality issues exist during the operational phase. The paper concluded that the adoption of unrealistic assumptions was a key factor in the optimism of the closure plans.

Whilst water management is one factor leading to lengthy periods of site management prior to relinquishment, the examples of Section 2 show that there are also other factors. These are often ignored, with closure plans assuming very short monitoring periods and little requirement for site management and maintenance. As has been discussed, the reality is different. Clearly incorrect and optimistic assumptions about the medium to long-term management of sites prior to relinquishment have major implications for:

- Community and regulator expectations.

- Corporate understanding and recognition of legacy liabilities.

- Corporate reputation.

- Cost.

Community groups and regulators might be led to believe, through optimistic closure plan assumptions, that a site will return to the community control sooner than can actually occur. This could lead to a breakdown in community and regulator trust, further leading to potential impacts on approvals for future mining projects in the region. It could also have negative impacts on community plans that have been put in place based on future land uses.

If closure plans are too optimistic about the potential length of time for site relinquishment, corporate management may realise that what they thought was a short-term liability, is in fact a liability that will sit on their books for many years or potentially in perpetuity. Had corporate management realised that there was a risk of longer term site management, they may have opted for a different closure strategy.

Having one or multiple sites failing to achieve relinquishment in the planned timeframe damages the credibility of the company, not just with the local community and regulator. On a global scale, the company's credibility can be damaged with the investment community as well as with non-governmental organisations and regulators in other countries where the company is operating. There is less damage to corporate reputation by being transparent about the uncertainties regarding long-term site management assumptions and demonstrating that they have been taken into consideration in the closure plan and the closure cost estimate.

Clearly a longer time frame for site management will result in additional costs. The risk of these additional costs being incurred needs to be considered for closure budgets and for the development of closure provisions. The impact of such cost increases will vary, depending on the reasons for the increased site management time frame. If for example, the closure plan wrongly assumed that no medium to long-term water treatment would be required then the cost increase could be significant, perhaps moderated to some extent by the effect of discounting over the longer periods.

As discussed, more often than not closure plan assumptions are optimistic. In some cases, however, they are overly conservative. This can have significant implications if the assumptions are not acknowledged and documented. Often inbuilt conservatism is not easily recognised. This could lead to wrong decisions being made about the preferred closure strategy if not all options are being considered from the same bases. It could also lead to inflated closure cost estimates with contingencies being added to contingencies. 
In summary, underlying assumptions that are not identified and acknowledged lead to poor decision-making, because the associated risks are harder to identify. This in turn has the potential to increase costs, limit flexibility to respond to changing circumstances and reduce trust with key stakeholders.

\section{$4 \quad$ What to do?}

The previous sections have discussed examples of assumptions, many of which are optimistic, and the consequences of not accounting for assumptions in closure plans. As also discussed, assumptions are a necessary component of closure plans and even adopting optimistic assumptions might be acceptable, depending on the circumstances of the site. What is not acceptable however, is a failure to identify, document and acknowledge the inherent uncertainties of all assumptions in the closure plan.

The identification and review of assumptions should commence when closure concept options are first being developed and continue through to final closure implementation. The earlier that assumptions are identified and comprehensively documented, the more readily can vulnerabilities in the closure plan be managed and rectified. Identifying assumptions at the stage where closure concept options are being assessed will enable a robust and defensible approach to the evaluation of closure options and the selection of the preferred closure strategy. The process of continually interrogating the underlying assumptions will then need to be repeated through each iteration of the preferred closure concept and closure plan. Figure 1 presents a simplified schematic of the approach that should be adopted throughout the entire closure planning process.

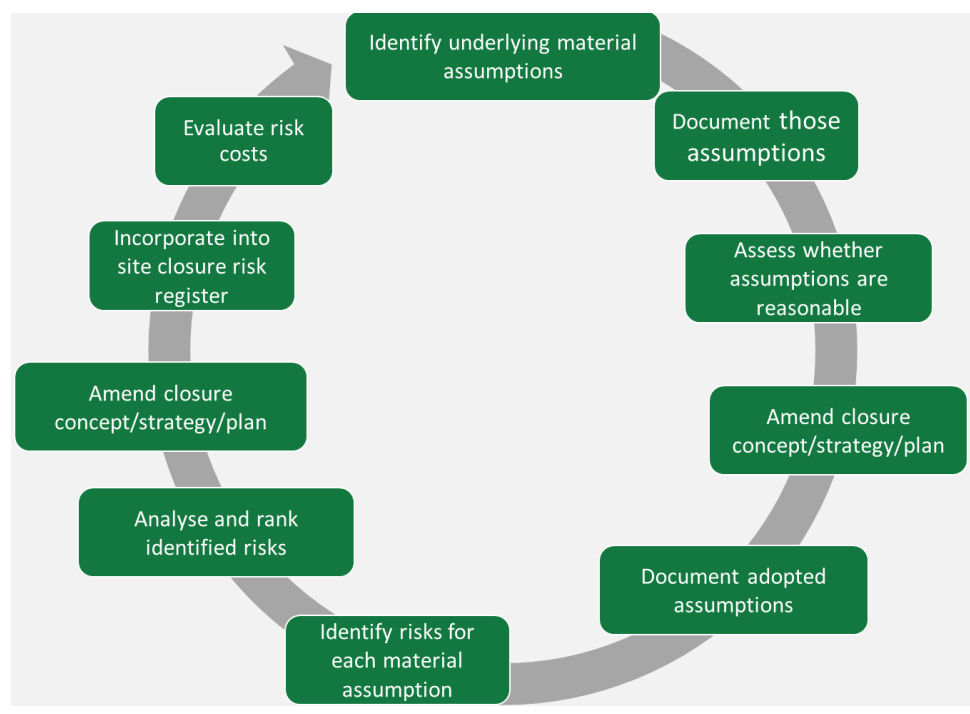

Figure 1 Management of closure assumptions

\subsection{Identifying, assessing and documenting underlying assumptions}

It is important to understand and identify the assumptions that underlie the closure concept and ultimately the closure design for the preferred closure strategy.

It is just as important not to confuse terminology. Many closure plans list assumptions, but they do not identify the underlying assumptions. For example, '...a waste rock dump with overall slope of 1 in 3 has been assumed...' is not an assumption; it is a design parameter that has been adopted for the closure plan. Underlying assumptions are that the waste rock dump will have long-term stability with a slope of 1 in 3 and that there will be stakeholder acceptance of that proposed landform. It is therefore important to understand the uncertainties associated with this assumption - and hence the likelihoods and consequences of the risk of long-term instability with a 1 in 3 slope and the risk of non-acceptance by stakeholders.

Once the underlying assumptions have been identified those that can have a material impact on the closure outcome need to be documented. This is an essential task to aid in the formulation of the assumption itself and to provide the basis for formal (and ongoing) documentation to be included in future closure plans. 
A review stage is then needed to assess whether it is reasonable to adopt the identified assumptions. How practical and feasible will the closure plan be, if it is to be based on those assumptions?

If some assumptions need changing, amendments will be required to the closure concept, strategy or plan, depending upon the stage of the closure process. Such changes may be fairly minor, although they could comprise significant changes to the closure concept - or it may be that an alternative closure option warrants further evaluation.

After completion of changes to the closure concept, strategy or plan the previously documented assumptions will need to be changed. This documentation of the adopted closure assumptions should then be included in the current closure plan.

\subsection{Identifying and analysing associated risks}

The closure plan, however, cannot simply just list the underlying assumptions and thereafter ignore them. The implications of the assumption not eventuating need to be assessed and associated risks identified. This will comprise identifying the consequence or consequences if the assumption is not realised and the likelihood or likelihoods of that risk event and consequence(s) occurring.

This risk identification and analysis stage will result in a list of ranked risks. An assessment will be needed on which of those risks can be tolerated. For those risks that cannot be tolerated, risk controls have to be identified to either eliminate the risks or to reduce them to an acceptable level. Those controls then have to be incorporated as integral components into the closure plan and a revision to the closure concept or plan, and the underlying assumptions, may be required. Once again, this feedback loop may result in relatively minor changes, or may result in significant changes or the adoption of a different closure strategy option. Depending on the extent of the identified controls this is also likely to require a revision of the closure cost estimate.

The final, ranked residual risks need to be incorporated into the closure risk register, which also forms part of the closure plan. The residual risks in the closure risk register must be accounted in the closure cost estimates. The risk cost is a critical element to the estimate of a closure cost estimate - primarily because closure plans have many underlying assumptions and often, therefore, a high degree of uncertainty. Closure cost estimates that do not account for the cost of risks are not representative of the potential closure liability.

\section{Conclusion}

All closure plans are based on underlying assumptions. Many closure plans do not identify these assumptions. Those closure plans which do list assumptions, often describe design parameters and not the assumptions that underlie those design parameters. Without documenting the underlying assumptions, the uncertainties and vulnerabilities of a closure plan cannot be easily recognised and addressed.

This can lead to closure plans that are not robust and not based on the results of detailed engineering, research, studies and trials as well as the use of sound professional judgement. Importantly, closure risks cannot be thoroughly identified and accounted in the closure plan. Risks are corollaries of assumptions. Risks exist if assumptions are not realised. Therefore, closure plan iterations must have a process where they are continually interrogated to identify the underlying assumptions which then must documented and incorporated into the closure plans. The closure risk assessment process must start with the documented assumptions, analyse and rank the associated risks; identify and cost risk controls; and incorporate the cost of the residual risks into the overall closure cost estimate.

\section{References}

Byrne, GM \& Hancock, JS 2018, 'Long-term water management - the forgotten legacy of mine closure', From Start to Finish: Life-ofMine Perspective, Australasian Institute of Mining and Metallurgy, Spectrum 24, pp. 209-215. 